\title{
Some Algebraic Properties of Multigranulations and an Analysis of Multigranular Approximations of Classifications
}

\author{
B.K.Tripathy \\ SCSE, VIT University, Vellore-632014, Tamilnadu, India \\ E-mail:tripathybk@vit.ac.in \\ R.Raghavan \\ SITE, VIT University, Vellore-632014, Tamilnadu, India \\ E-mail: rraghavan@vit.ac.in
}

\begin{abstract}
Ever since the introduction of rough sets by Pawlak as a model to capture uncertainty, it has drawn much attention from both theoretical and application point of view. Classifications of universes play very important roles in several fields of study. The study of rough definability of classifications was initiated by Busse. The properties of approximations of classifications were established in the form of four theorems and were used to define the types of classifications. These results were generalised to develop two theorems of necessary and sufficient type were established by Tripathy et al, from which several results including the four theorems of Busse could be derived as corollaries. Recently, rough sets based on Multigranulation were introduced and studied by Qian et al. Also, it has been extended to include incomplete information systems. Many of these results are extended to the multigranular cases. In this paper, we extend the properties of types of classifications to the multigranular context. Also, we introduce some parameters like the accuracy of approximation and the quality of approximation of classifications with respect to Multigranulations. We have obtained interesting criteria under which both types of Multigranulations reduce to single granulation. Also, some algebraic properties of Multigranulations are derived.
\end{abstract}

Index Terms- Rough Sets, Optimistic Multigranulation, Pessimistic Multigranulation, Classification, Approximations

\section{Introduction}

Rough set ${ }^{[1]}$ is one of the best models in today's world to model uncertainty in data and analyse. The basic model introduced by Pawlak depends upon equivalence relations defined over a universe of discourse. In fact, in this approach a rough set is represented by a pair of crisp sets called the lower and upper approximations. Classification of universes play very important role in rough set theory. Approximations of classifications introduced and studied by Busse ${ }^{[2]}$ reveals some important and interesting results. It has been observed that not all properties of individual rough sets can be extended to the case of classifications. In fact Busse $^{[2]}$ established four theorems as properties of classifications and these results could be used in generation of rules.

As noted by Pawlak ${ }^{[3]}$ the study of approximation of classification would shed lights on complements in case of mu ltivalued logic. Tripathy et al ${ }^{[4,5]}$ have unified the four theorems of Busse in the sense that they established two theorems of the necessary and sufficient type, from which several results including the theorems of Busse can be derived. Also, their results confirm to the prediction of Pawlak. These four theorems are important for deriving rules from information systems ${ }^{[6,}$

7]. More importantly, it is shown here that there are 11 cases as far as the types of classifications from which only five were considered by Busse. However, the other types of classifications reduce either directly or indirectly to the five cases considered by Busse. Another interesting aspect of the results in ${ }^{[4,5]}$ is the enumeration of possible types ${ }^{[3,8,9]}$ of elements in a classification, which is based upon the types of rough sets introduced by Pawlak ${ }^{[3]}$ and carried out further by Tripathy et al ${ }^{[4,5]}$.

The above results on approximation of classifications fro $m$ the granular computing point of view depend upon single granulation. Recently, two types of Multigranulations using rough sets were introduced in the literature. These are termed as optimistic ${ }^{[10]}$ and pessimistic ${ }^{[11]}$ Multigranulation. In this paper, we have attempted to extend the results of Tripathy et al ${ }^{[4,5]}$ to the Multigranulation context. The study of types of basic rough sets from the optimistic as Multigranulation point of view is done in ${ }^{[12,13]}$ and from the pessimistic Multigranulation point of view is done in ${ }^{[13]}$. In this paper, we start with the establishment of some algebraic 
properties of multigranular rough sets. In fact we find out the conditions under which the two types of Multigranulations reduce to single granulation. Also, sufficient conditions for two inclusions to be equalities in the optimistic Multigranulation case, which are equalities under single granulation are obtained and are shown to be not necessary.

The organization of the rest of the paper is as follows. In section 2 we present some definitions and notations to be used throughout the paper. We state some of the existing properties of multigranulations in section 3 followed by some interesting algebraic properties on multigranulations. Section 4 comprises of some theorems on approximation of classifications in multigranulations. Some measures of quality of mu ltigranular approximations and their properties are presented in section 5. We conclude the work done in the paper in section 6 and provide references to different sources consulted during the compilation of this work in section 7.

\section{Definitions and Notations}

In this section we provide some definitions and notations to be used throughout this paper.

\subsection{Basic Rough Set Theory}

Let $\mathrm{U}$ be a universe of discourse and $\mathrm{R}$ be an equivalence relation over $U$. By $U / R$ we denote the family of all equivalence classes of $R$, referred to as categories or concepts of $\mathrm{R}$ and the equivalence class of an element $\mathrm{x} \in \mathrm{U}$ is denoted by $[\mathrm{x}]_{\mathrm{R}}$. By a knowledge base, we understand a relational system $\mathrm{K}=(\mathrm{U}, \mathrm{P})$, where $\mathrm{U}$ is as above and $\mathrm{P}$ is a family of equivalence relations over $\mathrm{U}$. For any subset $\mathrm{Q}(\neq \phi) \subseteq \mathrm{P}$, the intersection of all equivalence relations in $\mathrm{Q}$ is denoted by $\operatorname{IND}(\mathrm{Q})$ and is called the indiscernibility relation over $\mathrm{Q}$. Given any $\mathrm{X} \subseteq \mathrm{U}$ and $\mathrm{R} \in \mathrm{IND}$ (K), we associate two subsets, $\underline{\mathrm{RX}}=\left\{\mathrm{x} \in \mathrm{U} /[\mathrm{x}]_{\mathrm{R}} \subseteq \mathrm{X}\right\} \quad$ and $\quad \bar{R} X=\left\{x /[x]_{R} \cap X \neq \phi\right\}$

called the R-lower and R-upper approximations of $X$ respectively. The R-boundary of $X$ is denoted by $B N_{R}(X)$ and is given by $\mathrm{BN}_{\mathrm{R}}(\mathrm{X})=\overline{\mathrm{RX}}-\underline{\mathrm{RX}}$. The elements of $\underline{R} X$ are those elements of $\mathrm{U}$, which can certainly be classified as elements of $X$, and the elements of $\bar{R} X$ are those elements of $\mathrm{U}$, which can possibly be classified as elements of $X$, employing knowledge of $\mathrm{R}$. We say that $\mathrm{X}$ is rough with respect to $\mathrm{R}$ if and only if $\underline{R} X \neq \bar{R} X$, equivalently $\mathrm{BN}_{\mathrm{R}}(\mathrm{X}) \neq \phi . \mathrm{X}$ is said to be R-definable if and only if $\underline{\mathrm{RX}}=\overline{\mathrm{R} X}$ or $\mathrm{BN}_{\mathrm{R}}(\mathrm{X})=\phi$.

\subsection{Rough Set Approximation Based on Multi - Granulations}

The concept of granular computing was introduced by Zadeh. According to this concept an equivalence relation on the universe can be regarded as a granulation, and a partition on the universe can be regarded as a granulation space. As mentioned earlier, from the granular computing point of view, two types of Multigranulations have been defined using rough sets.

The optimistic multigranular rough sets were introduced by Qian ${ }^{[10]}$ as follows. We note that in the beginning there was only one type of Multigranulation and it was not named as optimistic. After the development of a second type of Multigranulation, the first one was called optimistic and the second one was called as pessimistic. We note that we are considering double granulation only. For granulations of higher order, the definitions and properties are similar. The notations used for the two types of Multigranulations were different in the original papers. But we follow the notations used in a recent paper by Tripathy et al [ ${ }^{13]}$. That is we use $\mathrm{R}+\mathrm{S}$ for optimistic Multigranulation and $R * S$ for pessimistic Multigranulation, where $\mathrm{R}$ and $\mathrm{S}$ are two equivalence relations on $\mathrm{U}$.

Definition 2.2.1: Let $K=(U, \mathbf{R})$ be a knowledge base, $\mathbf{R}$ be a family of equivalence relations, $\mathrm{X} \subseteq \mathrm{U}$ and $R, S \in \mathbf{R}$. We define the optimistic multi-granular lower approximation and optimistic multi-granular upper approximation of $\mathrm{X}$ with respect to $\mathrm{R}$ and $\mathrm{S}$ in $\mathrm{U}$ as

$$
\underline{R+S} \mathrm{X}=\left\{\mathrm{x} \mid[\mathrm{x}]_{R} \subseteq \mathrm{X} \text { or }[\mathrm{x}]_{S} \subseteq \mathrm{X}\right\}
$$

and

$$
\overline{R+S} \mathrm{X}=\sim(\underline{R+S}(\sim X)) .
$$

Definition 2.2.2: Let $K=(U, \mathbf{R})$ be a knowledge base, $\mathbf{R}$ be a family of equivalence relations, $\mathrm{X} \subseteq \mathrm{U}$ and $R, S \in \mathbf{R}$. We define the pessimistic multi-granular lower approximation and pessimistic multi-granular upper approximation of $\mathrm{X}$ with respect to $\mathrm{R}$ and $\mathrm{S}$ in $\mathrm{U}$ as

$$
\underline{R * S} \mathrm{X}=\left\{\mathrm{x} \mid[\mathrm{x}]_{R} \subseteq \mathrm{X} \text { and }[\mathrm{x}]_{S} \subseteq \mathrm{X}\right\}
$$

and

$\overline{R * S} \mathrm{X}=\sim(\underline{R * S}(\sim X))$.

\subsection{Multi-granular} Classifications of 
We recall that a classification $F=$ $\left\{X_{1}, X_{2}, \ldots, X_{n}\right\}$ of a universe $\mathrm{U}$ is such that $\mathrm{X}_{\mathrm{i}} \cap \mathrm{X}_{\mathrm{j}}=\phi$ for $\mathrm{i} \neq \mathrm{j}$ and $\bigcup_{k=1}^{n} X_{k}=U$.

The approximations (lower and upper) of a classification $\mathrm{F}$ was defined by Busse as

$$
\underline{R F}=\left\{\underline{R}_{1}, \underline{R}_{2}, \ldots, \underline{R} X_{n}\right\}
$$

and

$$
\bar{R} F=\left\{\bar{R} X_{1}, \bar{R} X_{2}, \ldots \bar{R} X_{n}\right\}
$$

For any two equivalence relations $\mathrm{R}$ and $\mathrm{S}$ over $\mathrm{U}$, the lower and upper optimistic multigranular rough approximations and pessimistic multigranular approximations are defined in a natural manner as

$$
\begin{aligned}
& \left.\begin{array}{l}
\underline{\mathrm{R}+\mathrm{S} F}=\left\{\underline{\mathrm{R}+\mathrm{S}} X_{1}, \underline{\mathrm{R}+\mathrm{S}} X_{2}, \ldots, \underline{\mathrm{R}+\mathrm{S}} X_{\mathrm{n}}\right\} \\
\text { and } \\
\overline{\mathrm{R}+\mathrm{S}} \mathrm{F}=\left\{\overline{\mathrm{R}+\mathrm{S}} X_{1}, \overline{\mathrm{R}+\mathrm{S}} X_{2}, \ldots \overline{\mathrm{R}+\mathrm{S}} X_{\mathrm{n}}\right\}
\end{array}\right\} \\
& \underline{\mathrm{R} * \mathrm{~S}} \mathrm{~F}=\left\{\underline{\mathrm{R} * \mathrm{~S}} \mathrm{X}_{1}, \underline{\mathrm{R} * \mathrm{~S}} \mathrm{X}_{2}, \ldots, \underline{\mathrm{R} * \mathrm{~S}} \mathrm{X}_{\mathrm{n}}\right\} \\
& \text { and } \\
& \overline{\mathrm{R} * \mathrm{~S}} \mathrm{~F}=\left\{\overline{\mathrm{R} * \mathrm{~S}} \mathrm{X}_{1}, \overline{\mathrm{R} * \mathrm{~S}} \mathrm{X}_{2}, \ldots \overline{\mathrm{R} * \mathrm{~S}} \mathrm{X}_{\mathrm{n}}\right\}
\end{aligned}
$$

\section{Properties of Multigranulations}

We present below some properties of Multigranulations which shall be used in this paper to establish the results.

\subsection{Properties of Optimistic Multigranular Rough Sets}

The following properties of the optimistic multigranular rough sets were established in ${ }^{[10,11]}$.

$$
\begin{aligned}
& \underline{(\mathrm{R}+\mathrm{S})}(\mathrm{X}) \subseteq \mathrm{X} \subseteq(\mathrm{R}+\mathrm{S})(\mathrm{X}) \\
& \underline{(\mathrm{R}+\mathrm{S})}(\phi)=\phi=\overline{(\mathrm{R}+\mathrm{S})}(\phi), \\
& \underline{(\mathrm{R}+\mathrm{S})}(\mathrm{U})=\mathrm{U}=\overline{(\mathrm{R}+\mathrm{S})}(\mathrm{U}) \\
& \underline{(\mathrm{R}+\mathrm{S})}(\sim \mathrm{X})=\sim \overline{(\mathrm{R}+\mathrm{S})}(\mathrm{X}) \\
& \underline{(\mathrm{R}+\mathrm{S})}(\mathrm{X})=\underline{\mathrm{R} X} \cap \underline{\mathrm{S} X} \\
& \overline{(R+S)}(X)=\bar{R} X \cup \bar{S} X \\
& \left.\begin{array}{l}
\overline{(\mathrm{R}+\mathrm{S})}(\mathrm{X})=\underline{\overline{(\mathrm{S}+\mathrm{R})}}(\mathrm{X}), \\
\overline{(\mathrm{R}+\mathrm{S})}(\mathrm{X})=\overline{(\mathrm{S}+\mathrm{R})}(\mathrm{X})
\end{array}\right\} \\
& \underline{(\mathrm{R}+\mathrm{S})}(\mathrm{X} \cap \mathrm{Y}) \subseteq \underline{(\mathrm{R}+\mathrm{S}) \mathrm{X} \cap \underline{(\mathrm{R}+\mathrm{S})}}
\end{aligned}
$$

$$
\begin{aligned}
& \overline{(R+S)}(X U Y) \supseteq \overline{(R+S) X U} \overline{(R+S) Y} \\
& \overline{(R+S)}(X U Y) \supseteq \overline{(R+S) X U(R+S) Y} \\
& \overline{(R+S)}(X \cap Y) \subseteq \overline{(R+S) X \cap \overline{(R+S) Y}}
\end{aligned}
$$

\subsection{Properties of Pessimistic Multigranular Rough Sets}

The following properties of the pessimistic multigranular rough sets which are parallel to the properties in 3.1 were established in ${ }^{[11]}$.

$$
\begin{aligned}
& (\mathrm{R} * \mathrm{~S})(\mathrm{X}) \subseteq \mathrm{X} \subseteq \overline{(\mathrm{R} * \mathrm{~S})}(\mathrm{X}) \\
& \underline{(\mathrm{R} * \mathrm{~S})}(\phi)=\phi=\overline{(\mathrm{R} * \mathrm{~S})}(\phi), \underline{(\mathrm{R} * \mathrm{~S})}(\mathrm{U})=\mathrm{U}=\overline{(\mathrm{R} * \mathrm{~S})}(\mathrm{U}) \\
& \underline{(\mathrm{R} * \mathrm{~S})}(\sim \mathrm{X})=\sim \overline{(\mathrm{R} * \mathrm{~S})}(\mathrm{X}) \\
& \underline{(\mathrm{R} * \mathrm{~S})}(\mathrm{X})=\underline{\mathrm{R} X} \cap \underline{\mathrm{S} X} \\
& \overline{(\mathrm{R} * \mathrm{~S})}(\mathrm{X})=\overline{\mathrm{R} X U \overline{\mathrm{SX}}} \\
& (\mathrm{R} * \mathrm{~S})(\mathrm{X})=(\mathrm{S} * \mathrm{R})(\mathrm{X}), \overline{(\mathrm{R} * \mathrm{~S})}(\mathrm{X})=\overline{(\mathrm{S} * \mathrm{R})}(\mathrm{X}) \\
& \underline{(\mathrm{R} * \mathrm{~S})}(\mathrm{X} \cap \mathrm{Y}) \subseteq \underline{(\mathrm{R} * \mathrm{~S}) \mathrm{X} \cap \underline{(\mathrm{R} * \mathrm{~S})}} \mathrm{Y} \\
& \overline{(\mathrm{R} * \mathrm{~S})}(\mathrm{X} \cup \mathrm{Y}) \supseteq \overline{(\mathrm{R} * \mathrm{~S})} \mathrm{X} \cup \overline{(\mathrm{R} * \mathrm{~S})} \mathrm{Y} \\
& \underline{(\mathrm{R} * \mathrm{~S})}(\mathrm{X} \cup \mathrm{Y}) \supseteq \underline{(\mathrm{R} * \mathrm{~S}) \mathrm{X} \cup(\mathrm{R} * \mathrm{~S})} \underline{\mathrm{Y}} \\
& \overline{(\mathrm{R} * \mathrm{~S})}(\mathrm{X} \cap \mathrm{Y}) \subseteq \overline{(\mathrm{R} * \mathrm{~S})} \mathrm{X} \cap \overline{(\mathrm{R} * \mathrm{~S}) \mathrm{Y}}
\end{aligned}
$$

\subsection{Algebraic Properties of Multigranulations}

In this section we establish some algebraic properties of both types of Multigranulations. It is interesting to find conditions or the cases under which the two types of Multigranulations reduce to single granulation rough sets. In this section we find out the solutions to this problem.

Theorem 3.3.1: Let $\mathrm{R}$ and $\mathrm{S}$ be two equivalence relations on $\mathrm{U}$ and $X \subseteq U$. Then

$$
\underline{\mathrm{R}+\mathrm{S} X}=\underline{\mathrm{R} X} \text { and } \overline{\mathrm{R}+\mathrm{S}} \mathrm{X}=\overline{\mathrm{R} X}
$$

$$
\begin{aligned}
& \text { when } \mathbf{S}=\mathbf{U} \times \mathbf{U} \\
& \underline{\mathrm{R} * \mathrm{SX}}=\underline{\mathrm{R} X} \text { and } \overline{\mathrm{R} * \mathrm{~S} X}=\overline{\mathrm{R} X} \\
& \text { when } \mathrm{S}=\left\{\left.(\mathrm{x}, \mathrm{x})\right|^{x \in U}\right\} \text {. }
\end{aligned}
$$

\section{Proof of (29)}

$$
\begin{aligned}
& \text { In this case }[x]_{S}=U . \quad \text { So that } \\
& {[\mathrm{x}]_{\mathrm{S}} \subseteq \mathrm{X} \text { is not satisfied for any } \mathrm{X} \text { other than } \mathrm{U} \text { itself. }}
\end{aligned}
$$


So, if $X \neq U$ then ${ }^{[x]_{S}} \subseteq X$ is not satisfied for any $\mathrm{x}$ in U. Hence $\underline{R+S} X=\left\{x /[x]_{R} \subseteq X\right.$ or $\left.[x]_{S} \subseteq X\right\}$ reduces to $\left\{x /[x]_{R} \subseteq X\right\}=\underline{R} X$.

$$
\text { Also, } \overline{\mathrm{R}+\mathrm{S} X}=\sim \underline{\mathrm{R}+\mathrm{S}}(\sim \mathrm{X})=\sim \underline{\mathrm{R}}(\sim \mathrm{X})=\bar{R} X .
$$

\section{Proof of (30)}

In this case $[x]_{S}=\{x\}, \forall x \in U$. So that $\left.{ }^{[\mathrm{x}}\right]_{S} \subseteq \mathrm{X}$ is satisfied for any $\mathrm{x} \in \mathrm{X}$. Hence,

$$
\underline{R * S} X=\left\{x /[x]_{R} \subseteq X \text { and }[x]_{S} \subseteq X\right\} \quad \text { reduces to }
$$

$\left\{x /[x]_{R} \subseteq X\right\}=\underline{R} X$. As $\underline{R * S} X \subseteq X$, it is not necessary to consider elements $\mathrm{x}$ outside $\mathrm{X}$.

$$
\text { Also, } \overline{R * S} X=\sim \underline{R * S}(\sim X)=\sim \underline{R}(\sim X)=\bar{R} X \text {. }
$$

The proofs of the following properties of Multigranulations follow from their definitions:

Theorem 3.3.2: With the same notations as in Theorem 3.3.1, the following properties are satisfied by '+' and '*':

$$
\begin{aligned}
& \underline{R+S} X=\underline{S+R} X \text { and } \overline{R+S} X=\overline{S+R} X \\
& \underline{(R+S)+T} X=\underline{R+(S+T) X} \text { and } \\
& \overline{(R+S)+T} X=\overline{R+(S+T)} X \\
& \underline{R * S X}=\underline{S * R} X \text { and } \overline{R * S} X=\overline{S * R} X \\
& \underline{(R * S) * T X}=\underline{R *(S * T) X} \text { and } \\
& \overline{(R * S) * T} X=\overline{R *(S * T)} X
\end{aligned}
$$

Next, we prove two theorems which provide sufficient conditions for equality to hold in two inclusions in the Multigranulation case, which were true without any condition in the single granulation case.

Theorem 3.3.3: $[\bar{R} X \cap \bar{S} Y]=\phi$ and $[\bar{R} Y \cap \bar{S} X]=\phi$ is
a sufficient but not necessary condition
for $\overline{R+S}(X \cup Y)=(\overline{R+S} X) \cup(\overline{R+S Y})$.

Proof: We note that the following property hold for optimistic Multigranulation:

$$
\begin{aligned}
\overline{R+S}(X \cup Y)= & (\overline{R+S} X) \cup(\overline{R+S} Y) \cup \\
& {[\bar{R} X \cap \bar{S} Y] \cup[\bar{R} Y \cap \bar{S} X] }
\end{aligned}
$$

So, clearly the condition given is sufficient for the equality to hold. As expected, it follows from Theorem 3.3.1 and the following steps that the equality holds when $\mathrm{S}=U \times U$.

$$
\begin{aligned}
& \overline{R+S}(X \cup Y)=\bar{R}(X \cup Y), \quad \text { as above. Similarly, } \\
& \overline{R+S} X=\bar{R} X \quad \text { and } \quad \overline{R+S} Y=\bar{R} Y \quad \text {. Again, }
\end{aligned}
$$
side of (35) is equal to $\bar{R} X \cup \bar{S} Y$. However, $[\bar{R} X \cap \bar{S} Y]=\phi$ and $[\bar{R} Y \cap \bar{S} X]=\phi \quad$ may not satisfied in this case. Since ${ }^{[x]_{S}}=U$ for any $x \in U$, it follows that $\bar{S} X=\bar{S} Y=U$. So that $[\bar{R} X \cap \bar{S} Y]=\bar{R} X$ and $[\bar{R} Y \cap \bar{S} X]=\bar{R} Y$. So, the condition is not necessarily true.

Theorem 3.3.4: $\underline{R} X \bigcup \underline{S} Y=U$ and $\underline{R} Y \cup \underline{S} X=U$ is a sufficient but not neces sary condition for

$$
\underline{\mathrm{R}+\mathrm{S}}(\mathrm{X} \cap \mathrm{Y})=\underline{\mathrm{R}+\mathrm{SX} \cap \underline{\mathrm{R}+\mathrm{S}} \mathrm{Y} .}
$$

Proof: We note that the following property hold for optimistic Multigranulation:

$$
\begin{aligned}
& \underline{\mathrm{R}+\mathrm{S}}(X \cap Y)= \\
& \underline{\mathrm{R}+\mathrm{S} X} \cap \underline{\mathrm{R}+\mathrm{S} Y} \cap(\underline{\mathrm{R} X} \cup \underline{\mathrm{S} Y}) \cap(\underline{\mathrm{R} Y} \cup \underline{\mathrm{S} X})
\end{aligned}
$$

So, the condition is clearly sufficient for the equality to hold. As expected, it follows from Theorem 3.3.1 and the following steps that equality holds when $\mathrm{S}=U \times U$.

$$
\begin{aligned}
& \text { We have } \quad \underline{\mathrm{R}+\underline{\mathrm{S}}}(\mathrm{X} \cap \mathrm{Y})=\quad \underline{\mathrm{R}}(\mathrm{X} \cap \mathrm{Y}), \\
& \underline{\mathrm{R}+\mathrm{S} X}=\underline{\mathrm{R} X} \text { and } \underline{\mathrm{R}+\mathrm{SY}}=\underline{\mathrm{R} Y} \text {. Also, }(\underline{\mathrm{R} X} \cup \underline{\mathrm{S} Y}) \supseteq \underline{\mathrm{R} X} \\
& \text { and }(\underline{\mathrm{R} Y} \cup \underline{\mathrm{SX}}) \supseteq \underline{\mathrm{RY}} \text {. So, the right hand side of (36) is } \\
& \text { equal to the left hand side. Since }[\mathrm{x}]_{\mathrm{S}}=\mathrm{U}_{\text {for any }} x \in U, \\
& \text { it follows that } \underline{\mathrm{SX}}=\underline{\mathrm{S} Y}=\phi . \quad \text { So, }
\end{aligned}
$$
$(\underline{\mathrm{R} X} \cup \underline{\mathrm{S} Y})=\underline{\mathrm{R} X}$ and $(\underline{\mathrm{R} Y} \cup \underline{\mathrm{S} X})=\underline{\mathrm{R}} \mathrm{Y}$. So, the condition is not neces sarily true.

\section{Theorems on Approximations of Classifications in Multi-Granulations}

We use the notation in this section as $N_{n}=\{1,2,3, \ldots . n\}$

For any $I \subset \mathrm{N}_{n}, \mathrm{I}^{C}$ denotes the complement of $\mathrm{I}$ in $\mathrm{N}_{\mathrm{n}}$. 
Theorem 4.1: For any $I \subset \mathrm{N}_{\mathrm{n}}$

$$
\begin{aligned}
& \overline{R+S}\left(\bigcup_{i \in I} X_{i}\right)=\mathrm{U} \text {, if and only if } \\
& \overline{R+S}\left(\bigcup_{j \in I^{C}} X_{j}\right)=\phi . \\
& \underline{R * S}\left(\bigcup_{i \in I} X_{i}\right)=U \quad \text { if and only if } \\
& \left.\bigcup_{j \in I^{C}} X_{j}\right)=\phi .
\end{aligned}
$$

Proof: We only prove (37). The proof of (38) is similar. Only instead of (1) we have to use (2).

The proof follows from the equivalences below.

$$
\begin{aligned}
& \underline{R+S}\left(\cup_{j \in I^{C}} X_{j}\right)= \\
& \Leftrightarrow \quad \underline{R+S}\left(\mathrm{U} \backslash \cup_{i \in I} X_{i}\right)=\phi \\
& \Leftrightarrow \quad \sim \overline{R+S}\left(\bigcup_{i \in I} X_{i}\right)=\phi \quad \text { (by (1)) } \\
& \Leftrightarrow \quad \overline{R+S}\left(\bigcup_{i \in I} X_{i}\right)=\mathrm{U}
\end{aligned}
$$

Corollary 4.1: Let F, U, R and S be as in section 3 .

(i) If $\overline{R+S}\left(\bigcup_{i \in I} X_{i}\right)=\mathrm{U}$, then $\frac{R+S}{\mathrm{X}_{\mathrm{j}}=\phi}$ for each $\mathrm{j} \in \mathrm{I}^{\mathrm{C}}$.

$$
\text { If } \overline{\mathrm{R} * \mathrm{~S}}\left(\bigcup_{\mathrm{i} \in \mathrm{I}} \mathrm{X}_{\mathrm{i}}\right)=\mathrm{U} \text { then } \underline{\mathrm{R}+\mathrm{S}}\left(\mathrm{X}_{\mathrm{j}}\right)=\phi
$$

for each $\mathrm{j} \in \mathrm{I}^{\mathrm{C}}$.

Proof: By Theorem 4.1 and from the hypothesis we get $\underline{R+S}\left({ }_{j \in I}^{C^{C}} X_{j}\right)=\phi$. Now, as

$$
\frac{R+S}{\mathrm{X}_{\mathrm{j}}} \subseteq \underline{R+S}{ }_{\left(j \in I^{C}\right.} X_{j} \text { for each } \mathrm{j} \in \mathrm{I}^{\mathrm{C}} \text { the }
$$
conclusion in (i) follows.

Proof of (ii) is similar.

Corollary 4.2: For each ${ }^{i \in N_{n}}$,

$$
\text { (i) } \overline{R+S}\left(\mathrm{X}_{\mathrm{i}}\right)=\mathrm{U} \text { if and only if } \underline{\mathrm{R}+\mathrm{S}}\left(\mathrm{\textrm {j } \in \mathrm { i }} \mathrm{X}_{\mathrm{j}}\right)=\phi \text {. }
$$

(ii)

$$
\overline{\mathrm{R} * \mathrm{~S}}\left(\mathrm{X}_{\mathrm{i}}\right)=\mathrm{Uif} \text { and onlyif } \underline{\mathrm{R} * \mathrm{~S}}\left(\bigcup_{\mathrm{j} \in \mathrm{i}} \mathrm{X}_{\mathrm{j}}\right)=\phi .
$$

Proof: Taking $I=\{i\}$ in Theorem 4.1 we get these results

Corollary 4.3: For each $i \in N_{n}$

$$
\begin{aligned}
& \text { (i) } \left.\frac{R+S}{\left(X_{i}\right)=\phi \text { if and if } \overline{R+S}\left(\bigcup_{j \neq i} X_{j}\right.}\right)=U . \\
& \text { (ii) } \underline{R * S}\left(X_{i}\right)=\phi \text { if and only if } \overline{R * S}\left(\bigcup_{j \neq i} X_{j}\right)=U .
\end{aligned}
$$

Proof: Taking $I=\{i\}^{\mathrm{C}}$ in Theorem 4.1 we get this result.

Corollary 4.4: (i) If there exists $i \in N_{n}$ such that $\overline{\mathrm{R}+\mathrm{S}} \mathrm{X}_{\mathrm{i}}=\mathrm{U}_{\text {then for each }} \mathrm{j}(\neq \mathrm{i}) \in \mathrm{N}_{\mathrm{n}}, \underline{\mathrm{R}+\mathrm{S}} \mathrm{X}_{\mathrm{j}}=\phi$.

(ii)If there exists $\mathrm{i} \in \mathrm{N}_{\mathrm{n}}$ such that $\overline{\mathrm{R} * \mathrm{~S}} \mathrm{X}_{\mathrm{i}}=\mathrm{U}$ then for each $j(\neq i) \in N_{n}, \underline{R * S X_{j}}=\phi$.

Proof: (i) From Corollary 4.2,

$$
\begin{aligned}
& \overline{R+S} X_{i}=U \Rightarrow \underline{R+S}\left(\bigcup_{j \neq i} X_{j}\right)=\phi \\
& \Rightarrow \underline{R+S} X_{j}=\phi ; \text { for each } j \neq i .
\end{aligned}
$$

Proof of (ii) is similar.

Theorem 4.2: For any $I \subset \mathrm{N}_{\mathrm{n}}$,

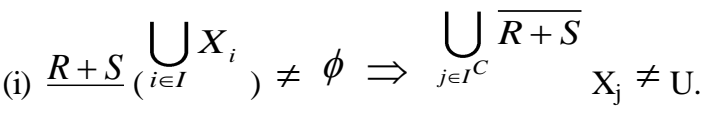
(ii)

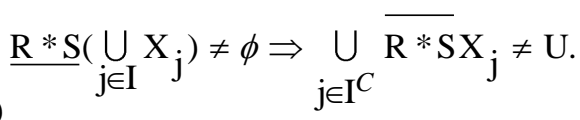

Proof: By (16)

$$
\underline{\mathrm{R}+\mathrm{S}}\left(\bigcup_{\mathrm{j} \in \mathrm{I}} \mathrm{X}_{\mathrm{j}}\right) \neq \phi \Rightarrow
$$

$\exists \mathrm{x} \in$ Usuch that $[\mathrm{x}]_{\mathrm{R}} \subseteq \bigcup_{\mathrm{j} \in \mathrm{I}} \mathrm{X}_{\mathrm{j}}$ or $[\mathrm{x}]_{\mathrm{S}} \subseteq \bigcup_{\mathrm{j} \in \mathrm{I}} \mathrm{X}_{\mathrm{j}}$.

Thus

$$
\left.{ }^{[x}\right]_{R} \cap\left(\bigcup_{j \in I^{C}} X_{j}\right)=\phi \text { or }[x]_{S} \cap\left(\bigcup_{j \in I^{C}} X_{j}\right)=\phi
$$




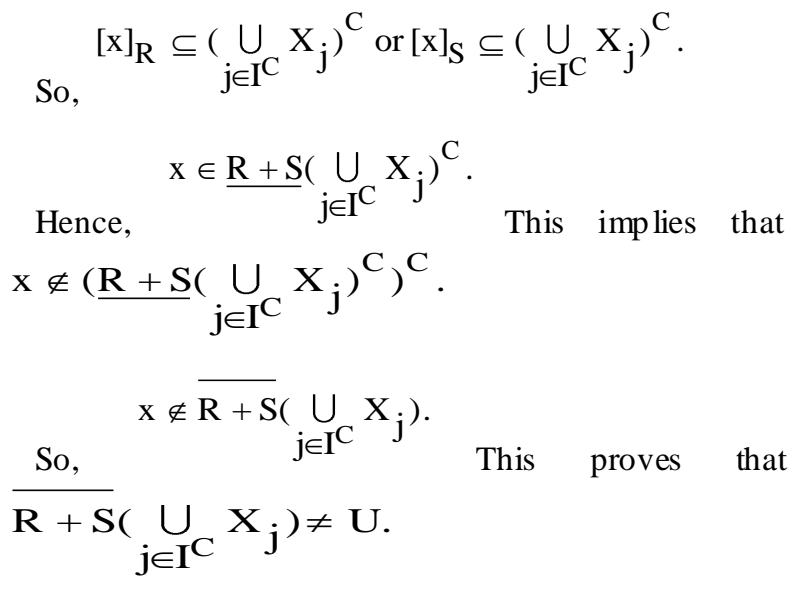

The proof of (ii) is similar.

Corollary 4.5: For each $\mathrm{I} \subset \mathrm{N}_{\mathrm{n}}$,

(i) If $\frac{R+S}{i \in I}\left(\bigcup_{i}\right) \neq \phi$ then $\overline{R+S} X_{j} \neq U$ for each ${ }^{\mathrm{j} \in \mathrm{I}^{\mathrm{C}}}$.

(ii) If $\stackrel{\mathrm{R} * \mathrm{~S}}{ }\left(\bigcup_{\mathrm{i} \in \mathrm{I}} \mathrm{X}_{\mathrm{i}}\right) \neq \phi$ then $\overline{\mathrm{R} * \mathrm{~S}} \mathrm{X}_{\mathrm{j}} \neq \mathrm{U}$ for each ${ }^{\mathrm{j} \in \mathrm{I}^{\mathrm{C}}}$.

Proof: We have by Theorem 4.2

$$
\overline{R+S}\left(\bigcup_{j \in I^{C}} X_{j}\right) \neq U .
$$

Hence, as

$$
\begin{aligned}
& \overline{R+S}\left(\underset{j \in I C}{C^{\prime}} X_{j}\right) \overline{R+S}\left(X_{j}\right), \forall j \in I^{C}, \text { it follows } \\
& \text { that } \overline{R+S} X_{j} \neq \text { Uforeach } j \in I^{C}
\end{aligned}
$$

Proof of (ii) is similar.

Corollary 4.6: For each $i \in N_{n}$,

(i) $\underline{\mathrm{R}+\mathrm{S}} \mathrm{X}_{\mathrm{i}} \neq \phi \Rightarrow \overline{\mathrm{R}+\mathrm{S}}\left(\bigcup_{\mathrm{j} \neq \mathrm{i}} \mathrm{X}_{\mathrm{j}}\right) \neq \mathrm{U}$.

(ii) $\underline{\mathrm{R} * \mathrm{~S}} \mathrm{X}_{\mathrm{i}} \neq \phi \Rightarrow \overline{\mathrm{R} * \mathrm{~S}}\left(\bigcup_{\mathrm{j} \neq \mathrm{i}} \mathrm{X}_{\mathrm{j}}\right) \neq \mathrm{U}$.

Corollary 4.7: If there exists $i \in N_{n}$ such that

(i) $\underline{R+S X_{i}} \neq \phi$ then for each $j(\neq i) \in N_{n}$, $\overline{\mathrm{R}+\mathrm{S}} \mathrm{X}_{\mathrm{j}} \neq \mathrm{U}$.

(ii) $\underline{\mathrm{R} * \mathrm{~S}} \mathrm{X}_{\mathrm{i}} \neq \phi$ then for each $\mathrm{j}(\neq \mathrm{i}) \in \mathrm{N}_{\mathrm{n}}$,
$\overline{R^{*} S} X_{j} \neq U$

Proof: (i) From corollary 4.6 we get $\overline{R+S}\left(\bigcup_{j \neq i} X_{j}\right) \neq U$.

So, as

$$
\overline{R+S}\left(\bigcup_{j \neq i} X_{j}\right) \supseteq \overline{R+S} X_{j} \text {, for } j \neq i
$$

we get the result. Proof of (ii) is similar.

Corollary 4.8: If for all $i \in \mathrm{N}_{\mathrm{n}}$,

(i)

$\underline{\mathrm{R}+\mathrm{S}} \mathrm{X}_{\mathrm{i}} \neq \phi$ holds then $\overline{\mathrm{R}+\mathrm{S}} \mathrm{X}_{\mathrm{i}} \neq \phi$ for all $\mathrm{i} \in \mathrm{N}_{\mathrm{n}}$

(ii) $\underline{\mathrm{R} * \mathrm{~S}} \mathrm{X}_{\mathrm{i}} \neq \phi$ holds then $\overline{\mathrm{R} * \mathrm{~S}} \mathrm{X}_{\mathrm{i}} \neq \phi$ for alli $\in \mathrm{N}_{\mathrm{n}}$.

\section{Proof: As}

$$
\underline{\mathrm{R}+\mathrm{SX}} \mathrm{k}_{\mathrm{k}} \neq \phi \text { for every } \mathrm{i} \in \mathrm{N}_{\mathrm{n}}, \text { it follows from }
$$

$\underline{R+S}\left(\bigcup_{j \neq i} X_{j}\right) \supseteq \underline{R+S} X_{k}(k \neq i) \quad$ that $\underline{R+S}\left(\bigcup_{j \neq i} X_{j}\right) \neq \phi$

Thus from Corollary 4.7 it follows that $\overline{\mathrm{R}+\mathrm{S}} \mathrm{X}_{\mathrm{i}} \neq \mathrm{U}$ for alli $\in \mathrm{N}_{\mathrm{n}}$.

Proof of (ii) is similar.

\section{Some Properties of Measures of Uncertainty}

In this section we introduce two measures, which describe inexactness of multigranular approximate classifications. These are extensions of the corresponding concepts used in the single granulation case.

We follow the same notations as used in the previous sections.

\subsection{Accuracy of Multigranular Approximations}

The accuracy of optimistic multigranular approximation of $\mathrm{F}$ by $\mathrm{R}$ and $\mathrm{S}$ is defined as

$$
\beta_{R+S}(F)=\frac{\sum_{i=1}^{n} \operatorname{card}\left(\underline{R+S} X_{i}\right)}{\sum_{i=1}^{n} \operatorname{card}\left(\overline{R+S} X_{i}\right)} .
$$

The accuracy of pessimistic multigranular approximation of $\mathrm{F}$ by $\mathrm{R}$ and $\mathrm{S}$ is defined as 


$$
\beta_{\mathrm{R} * \mathrm{~S}}(\mathrm{~F})=\frac{\sum_{\mathrm{i}=1}^{\mathrm{n}} \operatorname{card}\left(\underline{\mathrm{R} * \mathrm{~S}} \mathrm{X}_{\mathrm{i}}\right)}{\sum_{\mathrm{i}=1}^{\mathrm{n}} \operatorname{card}\left(\overline{\mathrm{R} * \mathrm{~S}} \mathrm{X}_{\mathrm{i}}\right)}
$$

As in the single granulation case, this measure expresses the percentage of possible correct decisions when classifying objects employing the knowledge of $\mathrm{R}$ and $\mathrm{S}$ taken together(optimistic or pessimistic manner).

\subsection{Quality of Multigranular Approximations}

The quality of optimistic multigranular approximation of $\mathrm{F}$ by $\mathrm{R}$ and $\mathrm{S}$ if given as

$$
\gamma_{\mathrm{R}+\mathrm{S}}(\mathrm{F})=\frac{\sum_{\mathrm{i}=1}^{\mathrm{n}} \operatorname{card}(\overline{\mathrm{R}+\mathrm{S} X})}{\operatorname{card}(\mathrm{U})} .
$$

The quality of pessimistic multigranular approximation of $\mathrm{F}$ by $\mathrm{R}$ and $\mathrm{S}$ if given as

$$
\gamma_{\mathrm{R} * \mathrm{~S}}(\mathrm{~F})=\frac{\sum_{\mathrm{i}=1}^{\mathrm{n}} \operatorname{card}(\overline{\mathrm{R} * \mathrm{~S} X})}{\operatorname{card}(\mathrm{U})}
$$

As in the single granulation case, this measure expresses the percentage of objects which can be correctly classified to classes of $\mathrm{F}$ employing the knowledge of $\mathrm{R}$ and $\mathrm{S}$ taken together (optimistic or pessimistic manner).

\subsection{Theorems on Approximations of Classifications}

Some properties of these measures were established in $^{[5]}$. We find that the same proofs work for both the multigranular cases. So, we only state below the results without any proof. We need the following additional definition.

Definition 5.3.1: (i) We say that a classification $F$ is $(\mathrm{R}+\mathrm{S})$-definable if and only if

$$
\underline{\mathrm{R}+\mathrm{SF}}=\overline{\mathrm{R}+\mathrm{S}} \mathrm{F}
$$

or equivalently

$$
\underline{\mathrm{R}+\mathrm{S}} \mathrm{X}_{\mathrm{i}}=\overline{\mathrm{R}+\mathrm{S}} \mathrm{X}_{\mathrm{i}} ; \mathrm{i}=1,2, \ldots \mathrm{n} .
$$

(ii) We say that classification $\mathrm{F}$ is $(\mathrm{R} * \mathrm{~S})$-definable if and only if

$$
\underline{\mathrm{R} * \mathrm{~S}} \mathrm{~F}=\overline{\mathrm{R} * \mathrm{SF}}
$$

or equivalently

$$
\underline{\mathrm{R} * \mathrm{~S}} \mathrm{X}_{\mathrm{i}}=\overline{\mathrm{R} * \mathrm{~S}} \mathrm{X}_{\mathrm{i}} ; \mathrm{i}=1,2, \ldots \mathrm{n} .
$$

Theorem 5.3.1: For any classification $\mathrm{F}$ in $\mathrm{U}$,

$$
\begin{aligned}
& \text { (i)F is }(\mathrm{R}+\mathrm{S}) \text {-definable if and only if } \\
& \beta_{\mathrm{R}+\mathrm{S}}(\mathrm{F})=\gamma_{\mathrm{R}+\mathrm{S}}(\mathrm{F})=1 . \\
& \text { (ii) } \mathrm{F} \text { is }(\mathrm{R} * \mathrm{~S}) \text {-definable if and only if } \\
& \beta_{\mathrm{R} * \mathrm{~S}}(\mathrm{~F})=\gamma_{\mathrm{R} * \mathrm{~S}}(\mathrm{~F})=1 .
\end{aligned}
$$

Theorem 5.3.2: For any classification $F$ in $U$ and equivalence relations $\mathrm{R}$ and $\mathrm{S}$ on $\mathrm{U}$,

$$
\begin{aligned}
& \text { (i) } 0 \leq \beta_{\mathrm{R}+\mathrm{S}}(\mathrm{F}) \leq \gamma_{\mathrm{R}+\mathrm{S}}(\mathrm{F}) \leq 1 \text {. } \\
& \text { (ii) } 0 \leq \beta_{\mathrm{R} * \mathrm{~S}}(\mathrm{~F}) \leq \gamma_{\mathrm{R} * \mathrm{~S}}(\mathrm{~F}) \leq 1 .
\end{aligned}
$$

\section{Conclusions}

In this paper, we have introduced the notions of mu ltigranular approximations of classifications for both types of Multigranulations. This is important from the rough set point of view as we use classifications for basic Multigranulations. We have established theorems, which are extensions of their single granulation versions. However, one of these results could not be extended in its full generality. We have proved some algebraic properties of Multigranulations, one of which answers the cases when Multigranulation reduces to single granulations. This result is important from the point of view that one would be interested to check the validity of conclusions obtained from Multigranulations by reducing to established results in the single granulation case. Also, we have illustrated this feature by trying to establish two equalities, which hold in the single granulation case but are not true in the Multigranulation case.

\section{References}

[1] Pawlak, Z.: Rough Sets, International Journal of Information and Computer Science, (1982), pp.341-346.

[2] Grzy mala Busse, J.: Knowledge acquisition under uncertainty- a rough set approach, Journal of Intelligent and Robotics systems, 1, (1988), pp. 3 16.

[3] Pawlak, Z.: Rough Sets, Theoretical Aspects of Reasoning about Data, Kluwer Academic Publishers, (1991).

[4] Tripathy, B.K.: On Approximation of classifications, rough equalities and rough equivalences, Studies in Computational Intelligence, vol.174, Rough Set Theory: A True Landmark in Data Analysis, Springer Verlag, (2009), pp.85 - 136. 
[5] Tripathy, B.K., Ojha, J., Mohanty, D. and Prakash Kumar, Ch. M.S: On rough definability and types of approximation of classifications, vol.35, no.3, (2010), pp.197-215.

[6] Chan, C.C. and Grzymala Busse, J.: Rough Set boundaries as a tool for learning rules from examples, In: Proceedings of the ISMIS-89, $4^{\text {th }}$ Int. Symposium on Methodologies for intelligent Systems, (1989), pp.281-288.

[7] Chan, C.C. and Grzymala Busse, J.: On the attribute redundancy and the learning programs ID3, PRISM and LEM2, Department of Computer science, University of Kansas, TR-91-14, 20 December, (1991).

[8] Pawlak, Z.: Rough Classifications, international Journal of Man Machine Studies, 20, (1983), pp.469- 483 .

[9] Tripathy, B.K. and Mitra, A.: Topological properties of rough sets and their applications, International Journal of Granular Computing, Rough Sets and Intelligent Systems (IJGCRSIS), (Switzerland),vol.1, no.4, (2010),pp.355-369

[10] Qian, Y.H and Liang, J.Y.: Rough set method based on Multi-granulations, Proceedings of the $5^{\text {th }}$ IEEE Conference on Cognitive Informatics, vol.1, (2006),pp.297 - 304.

[11] Qian, Y.H., Liang, J.Y and Dang, C.Y.: Pessimistic rough decision, in: Proceedings of RST 2010, Zhoushan, China, (2010), pp. 440-449.

[12] Tripathy, B.K. and Raghavan, R.: On Some Topological Properties of Multigranular Rough Sets, Journal of Advances in Applied science Research, Vol.2, no.3, (2011), pp.536-543.

[13] Tripathy, B.K. and Nagaraju, M.: On Some Topological Properties of Pessimistic Multigranular Rough Sets, International Journal of Intelligent Systems and Applications, Vol.4, No.8, (2012), pp.10-17.

\section{Authors' Profiles}

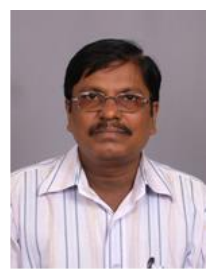

B.K Tripathy is a senior professor in the school of computing sciences and engineering, VIT University, at Vellore, India, has published more than 170 technical papers in international journals/ proceedings of international conferences/ edited book chapters of reputed publications like Springer and guided 12 students for $\mathrm{PhD}$. so far. He is having more than 30 years of teaching experience. $\mathrm{He}$ is a member of international professional associations like IEEE, ACEEE, CSTA, ACM, IRSS, CSI, IMS, OITS, OMS, IACSIT, IST and is a reviewer of around 35 international journals which include World Scientific,
Springer, Science Direct publications and IEEE. Also, he is in the editorial board of at least 12 international journals. His current research interest includes Fuzzy sets and systems, Rough sets and knowledge engineering, Granular computing, soft computing, bag theory, list theory and social network analysis.

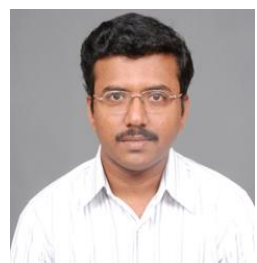

R.Raghavan is an Assistant Professor (Senior) in the School of Information Technology and Engineering (SITE), VIT University, at Vellore, India. He is pursuing his M.S., (By Research) degree from the same school. He is a life member of CSI. His current research interest includes Rough Sets and Systems, knowledge engineering, Granular Computing, Intelligent Systems.

How to cite this paper: B.K.Tripathy, R.Raghavan,"Some Algebraic Properties of Multigranulations and an Analysis of Multigranular Approximations of Classifications", International Journal of Information Technology and Computer Science(IJITCS), vol.5, no.7, pp.63-70, 2013. DOI: 10.5815/ijitcs.2013.07.08 